\title{
Revolucionário e ainda assim desconhecido!
}

(Weltbewegend und doch unbekannt!)

\author{
Peter M. Schuster ${ }^{1}$ \\ Recebido em 17/4/2007; Aceito em 21/6/2007
}

\begin{abstract}
O presente artigo consiste numa biografia do físico austríaco Chistian Doppler, criador do famoso efeito que leva o seu nome. Discute-se a recepção dada, em sua época, à sua descoberta, com particular atenção para as críticas que Doppler recebeu.
\end{abstract}

Palavras-chave: Christian Doppler, efeito Doppler, biografia científica, história da física.

This article describes the life and the scientific worf of the Austrian physicist Christian Doppler. It analises his most important scientifc discovery: the Doppler effect. This discovery was misunderstood at that time. It is also discussed why this happened.

Keywords: Christian Doppler, Doppler effect, scientific biography, history of physics.

\section{Introdução}

"Nenhuma inovação se firma sem resistência. Na verdade pode-se dizer que quanto menor a resistência encontrada e o quanto mais rapidamente o Novo se estabelece, mais rapidamente ele se torna obsoleto". Palavras proferidas por Hans-Georg Gadamer ${ }^{2}$ em seu discurso de abertura do Festival de Salzburgo de 1981. Poucas descobertas tiveram um caminho mais longo a percorrer que aquela feita por um físico nascido naquela cidade: Christian Andreas Doppler [1-5].

Não obstante a facilidade com que observamos o efeito no dia-a-dia, seja na variação do tom da sirene de um veículo que se aproxima e depois se afasta, quando notamos a mudança do tom de uma barra posta a girar ou do ruído de um inseto se aproximando de nosso ouvido, ainda assim foram necessárias duas décadas para que grandes experimentadores como Fizeau, BuysBallot e Mach conseguissem demonstrá-lo. ${ }^{3}$ Nem por isso o efeito Doppler se tornou, para as gerações posteriores, um experimento fundamental, pois nenhuma das histórias da física experimental, seja a de La Cour ou de Ramsauer, o menciona. ${ }^{4}$ Foi só em 1993, em Jena, que
Müller e Kuhne demonstraram de maneira clara o efeito Doppler [6]. Mesmo após 1845, com a comprovação experimental do efeito em acústica através de um experimento realizado por Buys-Ballot com um trem, sua validade teórica ainda foi negada durante décadas. Josef Petzval (1807-1891), um dos mais importantes matemáticos da antiga Áustria, iniciou em 1852 uma controvérsia sobre o tema com uma violência tal que a Real Academia de Ciências em Viena jamais vira em toda sua história. Partindo de quatro equações diferenciais por ele estabelecidas, Petzval deduziu de maneira impecável que "um pêndulo provido de um gerador de som produz o mesmo tom quer ele se mova, quer esteja em repouso". Uma semana antes da viagem à Veneza de seu antagonista Doppler, que já se encontrava em estágio terminal de doença, Petzval escreveu de maneira pouco contida:

Não se pode afirmar que a teoria de Doppler é desprovida de valor por explicar de maneira categoricamente errada o desenrolar de um fenômeno. Deve-se na verdade dizer que seu valor é antes de tudo negativo, uma vez que conduziu um grande número

\footnotetext{
${ }^{1}$ Publicado na Physik Journal 2(10), 47 (2003) por ocasião dos 200 anos do nascimento de Christian Andreas Doppler. Tradução e notas de S.R. Dahmen. E-mail: silvio.dahmen@ufrgs.br.

${ }^{2}$ Hans-George Gadamer (1900-2002), filósofo alemão discípulo de Heidegger. Sua filosofia pode ser encontrada em sua obra Wahrheit und Methode (Verdade e Método) [N.T.].

${ }^{3}$ Armand Hyppolite Louis Fizeau (1819-1896), físico francês, ficou conhecido por suas medidas da velocidade da luz. Christoph Heinrich Diedrich Buys-Ballot (1817-1890), físico holandês, ficou conhecido por seus trabalhos em meteorologia e o deslocamento de grandes massas de ar. Ernst Mach (1838-1916) físico austríaco, envolveu-se entre outras coisas com a física de ondas supersônicas [N.T.].

${ }^{4}$ Os livros aos quais o autor aqui se refere são o Grundversuche der Physik in historischer Darstellung. Von den Fallgesetzen bis zu den elektrischen Wellen (Experimentos fundamentais da física numa perspectiva histórica. Da queda livre às ondas eletromagnéticas) den elektrischen Wellen (Experimentos fundamentais da física numa perspectiva historica. Da queda livre às ondas eletromagnéticas)
do físo Carl Wilhelm Ramsauer (1879-1955) e o Historisk Fysik (Física Histórica) do meteorologista e professor do ensino médio dinamarquês Poul La Cour (1846-1908) [N.T.].
} 
de cientistas ao erro através de sua simplicidade e clareza, que nada mais são porém que superficialidade e falta de profundidade.

Mesmo depois que Ernst Mach conseguiu em 1860, aos 22 anos de idade, construir um aparelho para a verificação do efeito [7], obtendo assim a primeira demonstração sob condições de reprodutibilidade em laboratório ("não são muitos os que têm um trem à disposição como instrumento de laboratório"), o famoso astrônomo von Mädler, diretor do observatório em Dorpat, ${ }^{5}$ afirmou durante uma palestra perante a Academia de Ciências em Viena: "as fórmulas de Doppler deduzidas pelo Sr. Mach podem ser comprovadas na prática por outros métodos. Para isto a astronomia não serve de banco de provas".

Em 1879, 26 anos após a morte de Doppler, a Real Academia de Ciências da Bélgica premiou um trabalho do astrônomo Spée que contradizia o princípio de Doppler e Kayser ${ }^{6}$ formulava em seu Manual de Física de 1906 de maneira extremamente cuidadosa: "com base na teoria de elétrons formulada por A.H. Lorentz, parece que o efeito Doppler é necessariamente válido". Isto ocorreu no mesmo ano em que Einstein conclui que "independentemente da forma que a teoria eletromagnética deva ter, o princípio de Doppler e a aberração devem permanecer válidas".

Hoje é claro que seja através das medidas Doppler em geodésica global, nas técnicas navegacionais de Doppler no ar ou no espaço, do radar Doppler como auxiliar na previsão meteorológica ou suas aplicações na medicina e tecnologia como o sonógrafo Doppler para medir a velocidade do fluxo sanguíneo ou do anemômetro laser-Doppler para a velocidade de escoamento de fluidos, a descoberta em astronomia dos gases interestelares, a catalogação sistemática do desvio para o vermelho de 250 mil galáxias e com isto dados sobre a evolução e tamanho de nosso Universo - nenhum outro efeito mudou de maneira tão radical nossa visão de mundo como os conhecimentos obtidos a partir deste princípio.

\section{O homem por trás do efeito}

Por que o físico Christian Doppler não recebeu o merecido reconhecimento apesar de sua vasta obra? Por que só em 1988 a casa onde faleceu e seu túmulo foram redescobertos em Veneza [8]?

Não devemos procurar a razão no efeito em si, pois este é simples: quando dois objetos se encontram, podese estabelecer uma relação entre ambos - a ação mútua se torna mensurável. Visto assim, Doppler não alterou as bases da física. Ele apenas corrigiu um erro conceitual que atravancava seu desenvolvimento. Doppler não questionou a lei da constância do período de oscilação do pêndulo. Isto não o interessava. A ele interessava apenas o observável. Ele se manteve firme na sua radical afirmação de que "sempre que nos aproximamos de um pêndulo oscilante há um aumento no tom e, em nos afastando, uma diminuição do mesmo", criando assim um novo espaço para o pensamento científico.

Christian Doppler nasceu em 29 de novembro de 1803 em Salzburgo, numa casa localizada entre a residência onde viveu Mozart e a casa onde nasceu Herbert von Karajan. Seus antepassados haviam sido cinzeladores, cujas obras de arte ainda podem ser vistas em Salzburgo e arredores. ${ }^{7}$ Para seu pai porém logo se tornou claro que seu segundo filho não era fisicamente robusto para seguir a tradição da família. Assim ele recorreu ao professor de matemática e física do Liceu de Salzburgo, Simon Stampfer, que prontamente reconheceu o talento matemático do jovem Christian. Deste modo, em 1816, Doppler se tornou aluno de Stampfer [9]. Ao mudar-se para Viena, ele recomendou o jovem estudante para seu sucessor Adam Burg.

A importância destes dois mestres, Simon Stampfer e Adam Burg, para o florecimento dos talentos do jovem Christian não podem ser medidos em palavras: eles foram decisivos em sua vida. A marca de Stampfer é clara num texto escrito por Doppler muitos anos depois:

Ciências aplicadas sempre houve. Mas esta tão chamada prática não era mais do que algo no papel, e às chamadas ciências aplicadas faltava um pequeno detalhe: a verdadeira prática científica. A ciência aplicada mostra como aplicar os ensinamentos teóricos em casos reais; mas apenas isto. A prática científica no entanto os utiliza.

Doppler aprendeu com Stampfer esta mesma prática científica, que não apenas explica mas emprega. Doppler não se acanhava em trazer à luz questões tecnológicas. Ele descreveu ligas metálicas com as quais era possível fabricar espelhos que refletiam melhor; ele dominava técnicas hoje apenas dominadas por experimentados técnicos ópticos. Até seus últimos dias em Veneza ele trabalhou na melhoria do microscópio de reflexão e na escrita de um amplo e bem fundamentado tratado, trabalho este ainda citado por Hoppe em sua História da Óptica de 1926.

Adam Burg (1797-1882), o segundo professor importante na vida de Doppler, assumiu em 1828 a cadeira de matemática superior no Instituto Politécnico

\footnotetext{
${ }^{5}$ Johann Heinrich von Mädler (1794-1874), astrônomo alemão, diretor do observatório de Dorpat, atual Tartu, na Estônia. Entre seus muitos trabalhos, von Mädler determinou com precisão o chamado ano solar, sugerindo com isto a correção do calendário do Império Russo que se encontrava 12 dias atrasado em relação ao calendário utilizado no resto da Europa [N.T.].

${ }^{6}$ Heinrich Gustav Johannes Kayser (1853-1940), físico alemão que trabalhou principalmente com ondas acústicas [N.T.].

${ }^{7} \mathrm{O}$ termo alemão é Steinmetz. Estes profissionais eram, entre os pedreiros, responsáveis por esculpir as pedras que seriam utilizadas particularmente nas fachadas [N.T.].
} 
de Viena. Conhecedor do talento de Doppler, que ele havia conhecido em Salzburgo, ele sugeriu que este se tornasse seu assistente e permitiu que, sob seus cuidados, Doppler publicasse seus primeiros trabalhos científicos independentes.

\section{Primórdios elétricos}

Em Viena a atenção de Doppler na física desviou-se inicialmente para a teoria elétrica. O caminho por ele percorrido pode ser bem ilustrado pelo seguinte ditado de Lichtenberg: ${ }^{8}$ "O ensino da eletricidade já está aí, corriqueiro, tão exaurido e abandonado que, nas estradas principais nada mais há para se descobrir; deve-se buscar as estradas vicinais, além dos muros.".

Este método que poderíamos na verdade chamar de anti-método era típico do jovem Doppler. Seu trabalho Acerca de uma curiosa particularidade da diferença de potencial elétrico levou-o a concluir que "ao aparecimento de uma diferença de potencial está necessariamente associada uma mudança na forma do corpo eletrizado; uma barra metálica sob tensão deve encurtarse." O que movia Doppler era o desejo de estender seus experimentos para condutores, semicondutores e isolantes e utilizar as mudanças de forma assim obtidas na construção de novos eletrodos.

Visto que a posição de assistente era por definição limitada a 4 anos e que numa cidade tão biedermeieriana às margens do Danúbio ${ }^{9}$ as ciências eram tidas em baixa conta, Doppler em pouco tempo teve que procurar uma nova fonte de sustento. Durante um ano ele se manteve trabalhando como contador de uma tecelagem de algodão, quando então optou por emigrar para os EUA, vendendo para tanto todos os seus pertences (os livros inclusive). Mas o destino lhe reservara outro caminho: quando se encontrava em tratativas com o cônsul americano em Munique, foi informado que entre 15 concorrentes ele havia sido o escolhido para a cátedra de aritmética, álgebra e geometria do colégio técnico da cidade de Praga, ${ }^{10}$ cidade onde chegou em março de 1835. No ano seguinte casou-se com Mathilde Sturm, filha de um ourives de Salzburgo. Aí tiveram cinco filhos. Embora o casal não se sentisse muito em casa às margens do Moldava e Doppler buscasse posições em outras localidades do Império Austro-Húngaro, a família permaneceria 12 longos anos na cidade, o mesmo tempo que Kepler ali permanecera.

Um tratado de Doppler intitulado Algumas Considerações Acerca do Grande e do Pequeno na Natureza confirma seu precoce envolvimento com a questão atomística, embora apenas em 1853 sua mais importante contribuição ao assunto tenha sido publicada. Neste trabalho ele sugeriu experimentos que visavam reduzir a "multiplicidade de modelos" então vigentes, em particular da formulação de uma clara distinção entre átomos e moléculas. A este respeito Doppler constatou: "Não se pode postergar mais esta pergunta se quisermos dar um grande passo à frente na física teórica." Ele ainda afirma que "...A recusa em se debruçar sobre esta questão não tem outra origem que não a desfavorável e injustificável transposição de um conceito de infinito, originário de um processo puramente psicológico, às coisas que realmente existem no mundo físico."

É assim compreensível que os primeiros trabalhos originais de Doppler tenham chamado a atenção do matemático e filósofo Bernhard Bolzano (1781-1848). Este homem, que provavelmente é, entre os matemáticos do início do século XIX, aquele que formulou as mais profundas questões acerca dos fundamentos da análise, descreveu Doppler em uma carta de 1837 como um "amigo". 11 O que atraía Bolzano a Doppler era o método especulativo deste último, incomum à física da época, mas que se aproximava muito do método que Bolzano empregava na matemática. Seus próprios trabalhos eram pouco compreendidos em Praga e ainda hoje há grande quantidade de manuscritos de Bolzano não publicados.

Não menos importante na vida e obra de Doppler foi sua amizade com Franz Exner (1802-1853), ${ }^{12}$ em cuja hospitaleira casa ele se sentia totalmente à vontade. Exner sofrera, enquanto criança, com a falta de liberdade de pensamento da Áustria pré-revolucionária, embora não almejasse outra coisa que não o direito de ser simplesmente austríaco. ${ }^{13}$ Em 1832 Exner assumiu a cátedra de filosofia da Universidade de Praga, onde tornou-se o professor mais admirado. Seu salão,

\footnotetext{
${ }^{8}$ Georg Christoph Lichtenberg (1742 - 1799) foi o primeiro professor de física experimental na Alemanha (Göttingen). Talentoso escritor, ficou conhecido do público mais amplo por seus famosos aforismos, coletados num livro intitulado Sudelbuch, literalmente caderno de rascunhos [N.T.].

${ }^{9}$ Biedermeier é um termo alemão que designa um estilo de arte (visual e arquitetônica), literatura e música que marcaram o período entre 1815 e 1848 aproximadamente, em contraposição ao romantismo, que o precedeu. O termo vem do pseudônimo Gottlieb Biedermeier, usado por dois escritores que parodiaram a literatura da época, acusando-a de pequeno-burguesa e apolítica. O movimento tem na simplicidade e elegância das formas sua marca registrada [N.T.].

${ }^{10}$ Há no sistema austríaco e alemão três tipos de escolas secundárias: a Hauptschule, a Realschule e o Gymnasium. A Realschule seria o equivalente aos nossos colégios técnicos, enquanto o Gymnasium, de formação mais clássica, eram preparatórios para a Universidade. Doppler foi chamado para a Realschule de Praga [N.T.].

${ }^{11} \mathrm{O}$ termo amigo é de uso muito mais restrito ao que estamos habituados no Brasil. Por isso este comentário do autor para enfatizar o estreito grau de proximidade entre Doppler e Bolzano [N.T.].

${ }^{12}$ Pai do físico Franz Serafin Exner, sob cuja orientação estudaram Marian Smoluchowski, Stefan Meyer, Erwin Schrödinger, Karl Kohlrausch e Hans Thirring, entre outros [N.T.].

${ }^{13} \mathrm{O}$ autor se refere à revolução de março de 1848 que teve início na Alemanha e se estendeu para a Áustria. Os revolucionários dos diversos estados alemães lutavam por reformas democráticas e a unificação dos diferentes reinados e principados alemães em uma Liga Alemã [N.T.].
} 
nos quais o chamado Clube das Terças-Feiras se reunia, "assemelhava-se a uma academia onde as mais eruditas e brilhantes mentes de Praga circulavam". Foi aí que Doppler fez importantes amizades.

\section{Um efeito curioso}

Na reunião da Real Sociedade de Ciências da Boêmia no dia 25 de maio de 1842 Doppler apresentou sua opus magnus: Acerca do curioso surgimento de luz colorida das estrelas duplas e outras estrelas do firmamento. Tentativa de uma teoria geral que contém como parte integrante de si o Teorema da Aberração de Bradley [10]. Neste tratado ele formulou pela primeira vez a pergunta sobre o que aconteceria se o observador e a fonte se movessem um em relação ao outro: "Parece-me...que passou completamente despercebido que, quando se fala das ondas sonoras e luminosas como causa das sensações visuais e auditivas e não como eventos objetivos, não se deve perguntar em que intervalo de tempo ou com qual intensidade a geração de ondas em si ocorre, mas antes em que tempo e intensidade estas oscilações do ar e do éter são recebidas e sentidas pelos ouvidos e olhos do observador. Destas disposições puramente subjetivas e não das circunstâncias objetivas dependem a cor e intensidade da luz vista ou tonalidade e timbre de um som qualquer."

Doppler deduziu fórmulas e as discutiu no contexto de diferentes experimentos imaginários como exemplos de situações de variação de tom. Ele descobriu que se o observador se move com a velocidade do som para longe da fonte, as ondas sonoras não mais atingirão seu ouvido. No caso da fonte se mover com a velocidade do som para longe do observador, "[este] ouvirá o mesmo tom emitido pela fonte mas uma oitava abaixo."

Nos anos que se seguiram Doppler concentrou todas as forças no seu efeito: sem se deixar dispersar, ele pensou em possíveis conseqüências de sua descoberta, estimulou novos experimentos e descobriu assim um resultado que seria confirmado 40 anos depois por Mach e Salcher [11]: Doppler antecipou a relação entre o ângulo de abertura do cone de som e a velocidade da fonte emissora no artigo Acerca da influência do movimento do meio sobre os fenômenos das ondas no ar, água e éter [12]. Assim achamos em Doppler já definidos o cone e o ângulo de Mach, assim batizados por Prandtl em 1913 e pelo Professor J. Ackeret, ${ }^{14}$ de Zurique, em 1928. Doppler na verdade vai além de Mach, pois ele trata de frentes de onda curvas, causadas por exemplo por um movimento retilíneo acelerado ou desacelerado, ou pelo movimento a velocidade constante em uma trajetória curva. Com isso ele descreveu pela primeira vez o efeito de focalização da onda de choque que ocorre por exemplo no mergulho supersônico de um avião em curva e que só foi estudado muito depois - infelizmente sem qualquer menção ao trabalho de Doppler.

O Instituto Politécnico se encontrava então em fase de grande crescimento. Durante o período em que esteve em Praga, o número de estudantes de matemática passou de 126 a 441 e dos alunos de geometria prática decuplicou. A saúde frágil do incansável professor e pesquisador não condizia com tais tarefas. Na dupla função de secretário da Sociedade e professor sua carga de trabalho era gigantesca. Ele disse certa vez a Exner, sarcasticamente, que após o trabalho na Sociedade ele ainda tinha, "como descanso", que aplicar a prova em 800 alunos e corrigir 668 monografias. De acordo com o atestado médico do diretor clínico de Praga J. Oppolzer, Doppler deveria - ao menos durante o inverno ser eximido de quaisquer esforços que viessem a prejudicar sua laringe, "caso queiram evitar que isto acabe por levá-lo ao túmulo".

\section{Trabalho criativo em tempos difíceis}

Além do ano de 1842, o período compreendido entre janeiro e junho de 1846 representa a fase mais frutífera de seu trabalho. Neste curto período ele apresentou nada menos que 11 trabalhos científicos durante as reuniões da Sociedade das Ciências. E tudo quando já marcado pela doença, ${ }^{15}$ com um número sempre crescente de estudantes e a tensão política entre os tchecos e a casa imperial austríaca.

Com a ajuda de seus conhecidos Bolzano tentou achar uma outra posição para seu tão estimado amigo. Sua preocupação com Doppler está registrada numa carta datada de 7 de fevereiro de 1846 e enviada a Fesl: "Dia e noite, no verdadeiro sentido da palavra, mantenho-me ocupado com as fantásticas idéias com as quais o Prof. Doppler me motiva e que se sucedem umas às outras. É simplesmente indescritível o gênio criativo que a Áustria dispõe na figura deste homem". Ele menciona o tratado que Karl Kreil ${ }^{16}$ escrevera acerca de Doppler e se ele havia chegado às mãos das pessoas "das quais dependerá a salvação deste gênio para as ciências ou sua derrocada como Pégaso sob o jugo. Pois é de se esperar que o pior aconteça."

Doppler não se permitia uma pausa e publicou um artigo intitulado Acerca de uma maneira de tornar perceptíveis e de determinar movimentos periódicos extremamente rápidos. Ele se refere a trabalhos de Faraday e Stampfer, mas os critica por terem ambos achado que este fenômeno era apenas um instrutivo exemplo de uma ilusão de óptica. "Com isto", afirmou Doppler,

\footnotetext{
${ }^{14}$ Ludwig Prandtl (1875-1953), físico alemão famoso por seus estudos de aerodinâmica e pelo desenvolvimento da teoria de camadas limite. Formulou os princípios da aerodinâmica subsônica [N.T.].

${ }^{15}$ Doppler sofria de uma silicose, doença ocupacional comum entre pessoas que aspiraram muito pó [N.T.].

${ }^{16}$ Karl Kreil (1798-1862), meteorologista e astrônomo austríaco. Autor de importantes estudos sobre o magnetismo terrestre e inventor de uma série de instrumentos meteorológicos de registro automático de medidas [N.T.].
} 
"as muitas possibilidades de aplicação lhes passaram despercebidas."

A partir de 1845 Doppler passou a envolver-se com a fotografia e a fotometria, ou seja, os métodos que permitiriam comprovar a existência do fenômeno que ele previra. Estes métodos se mostrariam mais tarde de grande importância na comprovação e nas aplicações de seu princípio e causariam na astronomia uma revolução só comparável à invenção do telescópio. Em 1847 Doppler demonstrou uma maneira de como tratar matematicamente as cores, criando através da determinação de três padrões de medida de cor os fundamentos de uma teoria para sua mensuração. No mesmo ano, pouco antes de sua morte em 1848, Bolzano mais uma vez homenageou os estudos de Doppler e enumerou vários máquinas e equipamentos, dos quais "parte já foi construída e sua utilidade comprovada, parte apresentada aos examinadores da Sociedade [Científica] de Praga na forma de modelos ou descrições, sem que o grande público tomasse conhecimento do fato."

Em 1847 surgiu uma esperança de deixar Praga. Na Academia Florestal e de Minas da cidade de Schemnitz (atual Banská Štiavnica ${ }^{17}$ ), abriu-se uma vaga para a cátedra de matemática, física e mecânica. Doppler candidatou-se e a conseguiu. Porém, mal havia chegado a Schemnitz, então o mais importante centro minerador da Europa, tiveram início os levantes nacionalistas por todo o continente. No meio de toda a confusão de revoluções e guerra, Doppler foi chamado a ocupar a cátedra antes ocupada por Stampfer, que se aposentara, na cidade de Viena.

Após a retirada das tropas revolucionárias húngaras de Schemnitz, Doppler e a família mudaram-se para Viena, onde ele apresentou perante a Academia seu novo projeto: Acerca de uma fonte para observação da declinação magnética ainda não utilizada. Apesar dos tempos inquietos passados em Schemnitz, o estudo de altos mapas de minas inspiraram-no em um novíssimo tema de pesquisa.

\section{Reconhecimento tardio}

Neste período Doppler conseguiu finalmente um certo reconhecimento de seu trabalho. No dia 26 de janeiro de 1848 foi eleito membro da Imperial Academia de Ciências de Viena e no mesmo ano doutor honoris causa da Universidade de Praga. Em 1849 ele se encontrava de volta à cidade onde, como jovem assistente, recebera os primeiros impulsos da sua carreira. Seus promotores, Stampfer e Burg, trabalhavam no mesmo prédio que ele, enquanto seu amigo Exner ocupava, no ministério da educação, uma posição-chave na política educacio- nal. Neste ano, sob a direção do ministro Conde Leo Thun-Hohenstein, iniciaram-se profundas reformas no sistema de ensino. Estas reformas, formuladas por Exner e o berlinense Bonitz, ${ }^{18}$ estão entre as mais maduras criações da pedagogia de estado do século XIX e proporcionaram a Doppler aquilo que seus amigos sempre lhe almejaram: em 1850 ele foi nomeado o primeiro diretor do recém-fundado Instituto de Física da Universidade de Viena.

A construção do primeiro Instituto de Física da Universidade foi uma grande empreitada operacional, que Doppler, não obstante a doença, conduziu de forma conseqüente e enérgica. Ele conseguiu criar uma atmosfera especial que perdurou até seus sucessores, Stefan e Boltzmann, levando este último a alcunhá-lo de "o espírito de Erdberg". ${ }^{19}$ Doppler contratou funcionários, instalou uma biblioteca e rascunhou o estatuto da instituição, onde se pode ler: "Junto ao ensino e a orientação dos alunos, uma outra incumbência do conselho do instituto tão importante quanto estas é: promover a física como ciência através de pesquisa própria e independente." Assim, pela primeira vez na história universitária da monarquia a atividade de pesquisador não apenas era autorizada como enfaticamente apoiada.

\section{Morte prematura}

Em 1852 os problemas pulmonares de Doppler já haviam-no enfraquecido a tal ponto que seu médico insistiu para que ele passasse um período de licença médica numa região de clima mais ameno. Isso ocorreu concomitantemente com os ataques veementes de Petzval a sua teoria perante a Academia. Oito dias após a reunião onde a teoria de Doppler foi definitivamente declarada como "ultrapassada, comprovadamente errada", as autoridades deram-lhe uma licença de 6 meses para tratar da saúde. Em uma carta da mesma data mas apresentada à faculdade uma semana depois, a direção do Instituto foi passada a Ettingshausen. ${ }^{20}$ Não perturbado por toda a animosidade, Doppler ainda disse ao tribunal acadêmico as proféticas palavras:

Vivo ainda mais na certeza que a jóia de cores que maravilham os olhos daqueles que observam as estrelas duplas e outras estrelas do firmamento, mais do que um espetáculo para os olhos, nos servirão, num futuro ainda que longínquo, para determinar os elementos das trajetórias dos corpos celestes, cujas distâncias imensuráveis nos permitem hoje apenas o uso de meios puramente ópticos.

\footnotetext{
${ }^{17}$ Cidade da Eslováquia, onde se localizavam importantes minas de prata.

${ }^{18}$ Hermann Bonitz (1814-1888), filósofo alemão, responsável entre outras coisas pelo sistema de ensino empregado nos ginásios prussianos após 1882 [N.T.].

${ }^{19}$ Erdberg é a região da grande Viena onde se localizava o instituto [N.T.].

${ }^{20}$ Andreas Freiherr von Ettingshausen (1796-1878), matemático e físico alemão [N.T.].
} 
No dia 17 de março de 1853, em Veneza, Doppler falecia nos braços de sua esposa.

\section{Referências}

[1] P.M. Schuster, Weltbewegend-Unbekannt. Das Leben und Werk des Physiker Christian Doppler und die Welt danach (Edition Living, Pöllauberg, 2003).

[2] H. Grössing e K. Kadletz, Christian Doppler (18031853), Bd. 1 (Böhlau, Viena, 1992).

[3] P.M. Schuster, Christian Doppler (1803-1853), Bd. 2, Das Werk (Böhlau, Viena, 1992)

[4] I Stoll et. al., The Phenomenon of Doppler (The Czech Technical University, Faculty of Nuclear Sciences and Physical Engineering, Praga, 1992).

[5] A. Eden, The Search for Christian Doppler (Springer, Viena, 1992).

[6] J. Doerschner et. al., Die Sterne 69, 313 (1993).

[7] E. Mach, Beiträge zur Dopplerschen Theorie. Tonund Farbänderungen durch Bewegung. Gesammelte Ab- handlungen, Praga, 1873. Reproduzido na Ref. [3], p. 436.

[8] P. Schuster, Eine Rose für Christian Doppler, Ein Essay für einen Physiker, weltbewegend-unbekannt (Falter 15, Viena, 1989). Kurt Gödel, Collected Works (Ed. S. Feferman, Oxford University Press, Oxford, 1995), v. III.

[9] P. Schuster e C. Strasser, Simon Stampfer, 1790-1864. Von der Zauberscheibe zum Film (Schriftenreihe des Landespressebüros, Salzburgo, 1998), Serie Sonderpublikationen n. 142 .

[10] C. Doppler, Abhandlungen der königlich-böhmischen Gesellschaft der Wissenschaften (V. Folge, Bd. 2, Praga, 1843), p. 465. Reproduzido na Ref. [3], p. 173.

[11] C. Hoffmann e P. Berz (eds.), Über Schall. Ernst Machs und Peter Salchers Geschoßfotografien (Wallstein, Göttingen, 2001). Rev. Bras. Ens. Fis. 29, 281 (2006)

[12] C. Doppler, Abhandlungen der königlich-böhmischen Gesellschaft der Wissenschaften (V. Folge, Bd. 5, Praga, 1847), p. 293. Reproduzido na Ref. [3], p. 216. 